\title{
Plasma and Pancreatic Tissue Levels of Islet Amyloid Polypeptide in Type 1 and Type 2 Diabetes: A Review
}

\author{
Tatsuo Tomita* \\ Departments of Integrative Bioscience and Pathology, Oregon Health and Science University, 611 SW Campus Drive, Portland, OR 97239-3097, USA
}

\author{
Received: July 19, 2016; Accepted: September 25, 2016; Published: October 03, 2016 \\ *Corresponding author: Departments of Integrative Bioscience and Pathology, Oregon Health and Science University, 611 SW Campus Drive, Portland, OR \\ 97239-3097, USA, Tel: +503-646-5747; E-mail: tomitat39@gmail.com
}

\begin{abstract}
The etiology of type 2 diabetes includes obesity-associated insulin resistance, defective insulin secretion and loss of $\beta$-cell mass. Islets remodel at a delicate balance between regeneration and apoptosis. Ample amyloid deposit is a characteristic finding for type 2 diabetic islets and islet amyloid polypeptide (IAPP) is a chief component of amyloid deposits. It is concomitantly co-secreted with insulin from $\beta$-cells in response to glucose-induced insulin secretion. In insulinrequiring subjects with type 1 and type 2 diabetes, synthetic IAPP, Pramlintide ${ }^{28-30}$ works synergistically with insulin for a better glycemic control. A loss of soluble IAPP in $\beta$-cells coincides with dying $\beta$-cells by toxic small molecular weight IAPP oligomers. There is markedly reduced immunostaining for insulin and IAPP in type 1 diabetic islets whereas there is moderately reduced immunostaining with extracellular amyloid deposits in type 2 diabetic islets. Type 2 diabetic islets show variable amount of amyloid deposits from small to massive deposits with less insulin and IAPP immunostaining with disproportionally increased $\alpha$ - and $\delta$ - cells. Insulin-deficient $\beta$-cells contribute to initial hyperglycemia and massive amyloid sheets in islets contribute to sustained insulin and IAPP deficiency. Amyloid sheets surround remaining $\beta$-cells and mechanically obstruct insulin secretion and transport into the blood.
\end{abstract}

Keywords: Amyloidosis; $\beta$-cells; Glucose; Glucagon; Insulin; Islets; Islet amyloid polypeptide; Pancreas; Pramlintide; Type 1 and type 2 diabetes

\section{Introduction}

Islet Amyloid Polypeptide (IAPP), amylin, is a 37 amino acid polypeptide, that was originally isolated as the chief constituent of pancreatic islets from subjects with type 2 diabetes (T2DM) $[1,2]$. Amyloid deposit is a characteristic histopathological finding for type 2 diabetic islets, found in about $90 \%$ of the pancreas from subjects with T2DM [1-5]. IAPP is concomitantly co-secreted with insulin from $\beta$-cells into the blood stream in response to glucose- and amino acid-stimulated insulin secretion [4-6]. IAPP hyposecretion in the blood is well established in subjects with type 1 diabetes (T1DM) and insulin-requiring subjects with T2DM [7-11], and decreased IAPP in islets has been recently recognized in islets from subjects with T1DM and T2DM by immunocytochemical staining $[12,13]$. A synthetic IAPP, Pramlintide ${ }^{28,29,30}$ (pro-hIAPP) was approved by FDA in 2005 for treating diabetes and has been used together with insulin for treating for both T1DM and insulin-requiring T2DM subjects for a better glycemic control [14-17]. Due to several physiochemical characteristics, such as insolubility and a propensity to aggregate, native IAPP cannot be formulated as a pharmaceutical preparation [17]. Proline replacement for 2830 IAPP amino acids is amyloid breaker, which is suitable for pharmacologic treatment [17]. Pramlintide acetate injection is a soluble, non-aggregating, synthetic analogue of IAPP [17]. Pramlintide suppresses postprandial glucagon secretion, leading to a better glycemic control in both T1DM and insulin-requiring T2DM subjects, and also decreases gastric emptying and increase satiety, all of which contribute to weight loss and a better glycemic control in both T1DM and T2DM subjects [17].

\section{Plasma chemistry findings}

In healthy subjects, IAPP secretion in the blood matches with insulin secretion with a molar ratio of IAPP of insulin at about $5 \%$ that of insulin (Figure 1 A) [7] and IAPP in the blood increases after meals (Figure 1B) [7] whereas in subjects with T2DM IAPP in the blood does not increase after meals despite practically no difference in IAPP fasting levels between healthy individuals and subjects with T2DM (Figure 1B) [7]. In subjects with T1DM, the fasting IAPP levels are less than $1 / 3$ that of healthy individuals and there is no increase of blood IAPP levels after meals (Figure 1B) [15]. Thus, there is a relative deficiency of both insulin and IAPP secretion in subjects with T2DM whereas there is absolute deficient insulin and IAPP secretion in the blood from subjects with T1DM $[7,15]$. In subjects with T1DM, Pramlintide $60 \mu \mathrm{g}$ plus rapid acting insulin (lispro) markedly reduces postprandial plasma glucose compared to regular insulin or lispro insulin injection alone (Figure 2B and C ) [11]. In subjects with T2DM, Pramlintide $120 \mu \mathrm{g}$ and lispro insulin injections prior to meal moderately reduce plasma glucose compared with lispro insulin 
injection alone (Figure 2A) [11]. Another study with pediatric patients with T1DM, blood chemistry study was followed for $7 \mathrm{~h}$ after bolus insulin sc and a mixed meal containing $50 \mathrm{~g}$ of carbohydrate as follows: fasting plasma glucose levels were much higher in subjects with T1DM and plasma glucose levels immediately peaked after meal and stayed higher than that of controls (Figure 3A)[16]. Plasma insulin levels of control subjects increased fivefold above the baseline as compared to subjects with T1DM under insulin treatment, whose basal levels were more than fourfold that of control levels with a modest twofold increase of plasma insulin levels after a mixed meal (Figure 3B) [16]. Fasting IAPP levels of subjects with T1DM was about 40 $\mathrm{pm}(\mathrm{pmol} / \mathrm{l})$ at about $1 / 5$ to $1 / 6$ that of control subjects and did not present any increase of plasma IAPP levels after a mixed meal (Figure 3C). Glucagon levels did not differ in children with or without T1DM after a mixed meal (Figure 3D) [16] probably because these children with T1DM did not have enough time to develop $\alpha$-cell hyperplasia leading to hyperglucagonemia. Combined Pramlintide and insulin injection reduces plasma

A

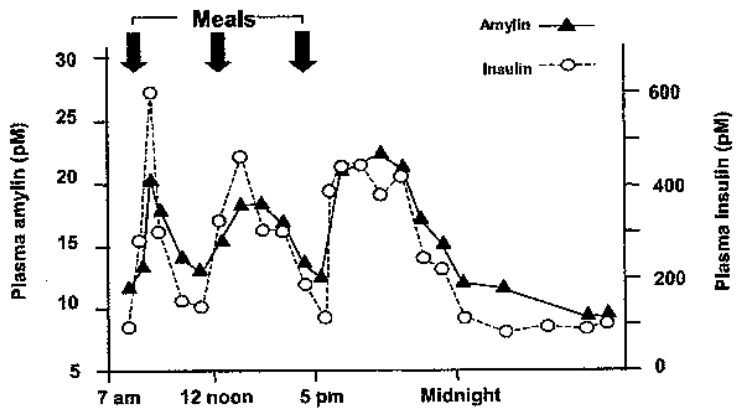

$\mathbf{B}$

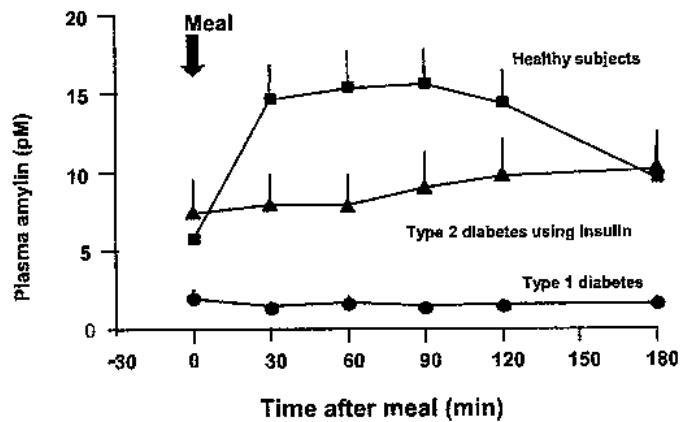

Figure 1: Plasma IAPP levels after meals in healthy adults and subjects with T1DM and T2DM

IAPP and insulin are secreted concomitantly in healthy subjects after meals. Plasma IAPP levels are less or about $5 \%$ that of insulin levels (A) (Reference 9, Kruger et al). After meal, healthy subjects secrete IAPP whereas subjects with T2DM reveal attenuated IAPP levels and subjects with T1DM show low base line and no response of IAPP secretion after meal (B). Kruger and Gloster, [15].
A
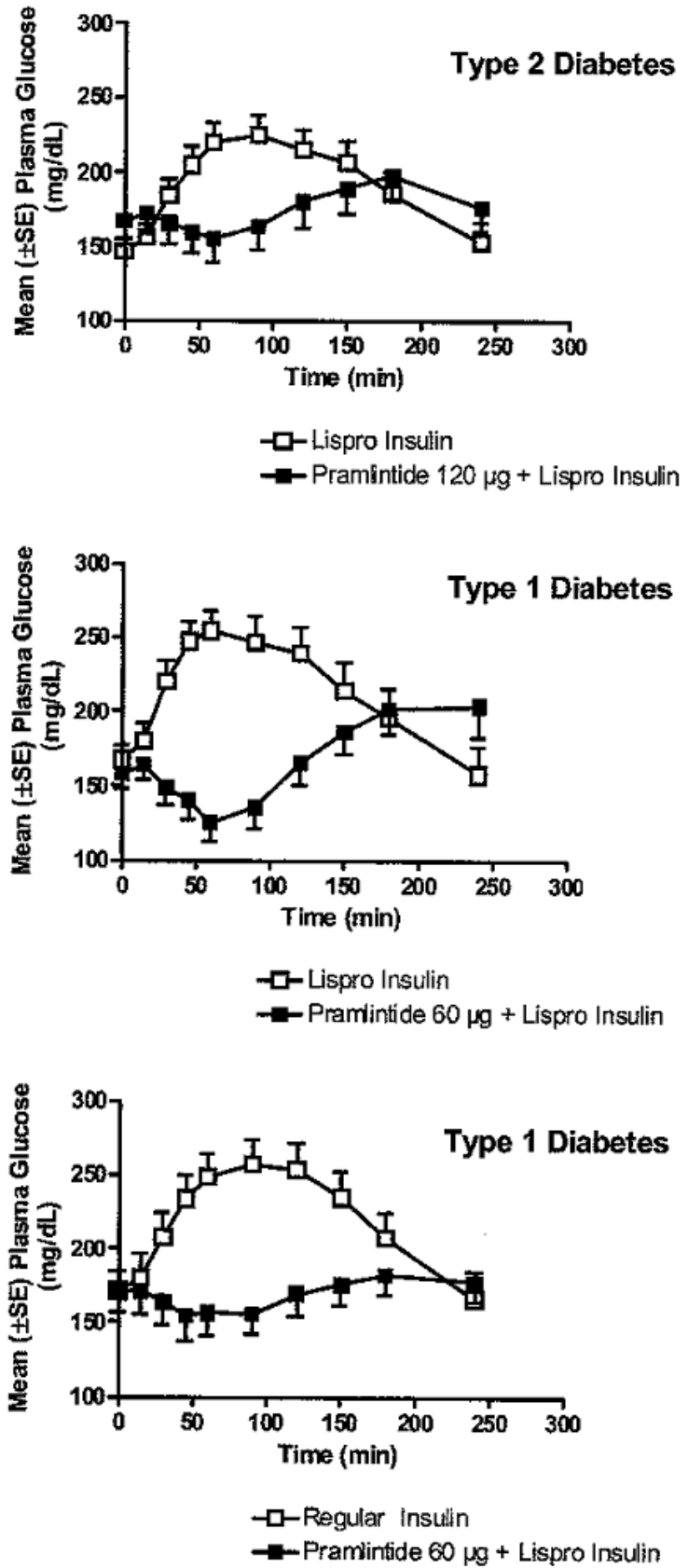

Figure 2: Effects of Pramlintide on plasma glucose in subjects with T1DM and T2DM

Subjects with T2DM were given rapid-acting insulin lispro with or without $120 \mu \mathrm{g}$ of Pramlintide immediately prior to a meal. Subjects with combined lispro insulin and Pramlintide showed relatively lower plasma glucose levels compared with subjects given to lispro insulin alone (A). Subjects with T1DM were given lispo insulin with or without Pramlintide $60 \mu \mathrm{g}$ prior to a meal. Plasma glucose levels were markedly lower than those with lispro insulin administered alone for $180 \mathrm{~min}$ (B). Subjects with T1DM were given regular insulin with or without Pramlintide $60 \mu \mathrm{g}$ prior to a meal. Subjects with combined regular insulin and Primlintide showed consistently lower plasma glucose levels for $240 \min (C)$ Maggs, DG, et al. [11]. 
A
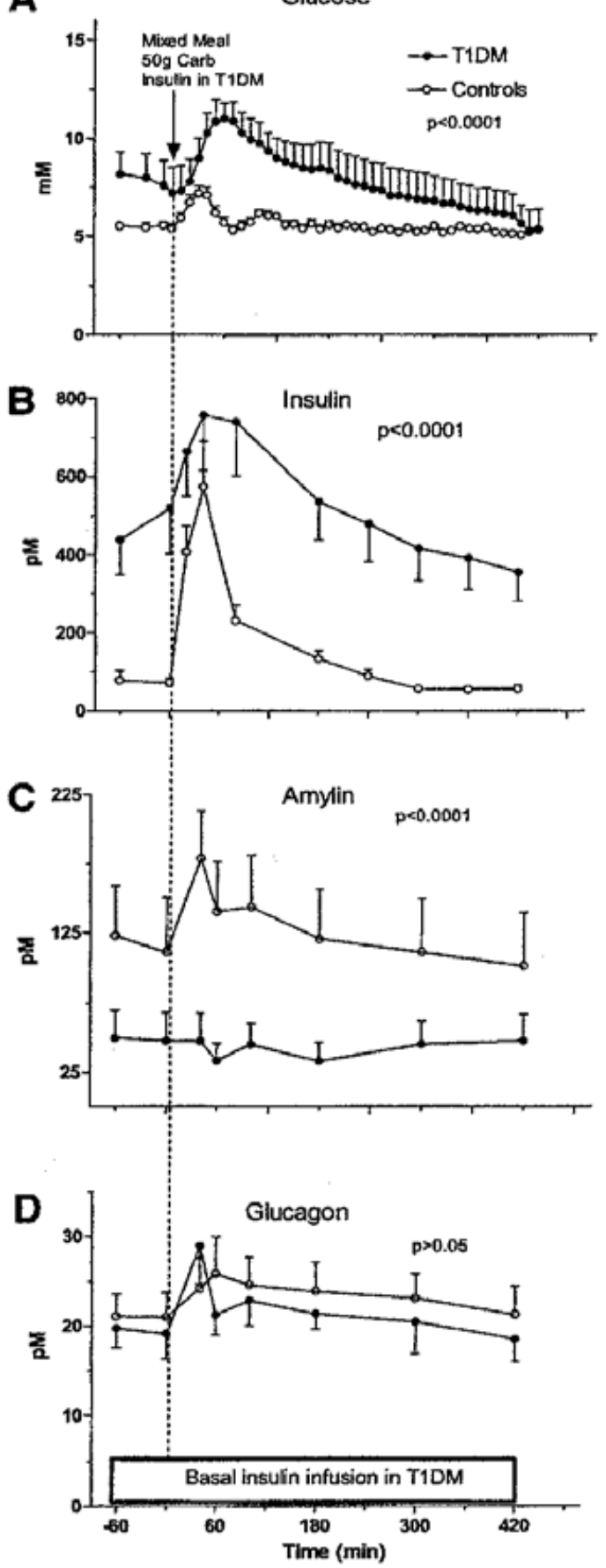

Figure 3: Plasma glucose, insulin, IAPP and glucagon levels after a mixed meal in pediatric patients with T1DM

Fasting glucose levels were much higher in diabetic patients and glucose levels peaked after meal, which stayed higher than that of control (A). After insulin sc and a mixed meal, insulin levels in the control subjects increased fivefold with baseline as compared to patients with T1DM, who revealed a modest twofold increase (Figure 3B). Fasting IAPP levels of patients with T1DM was about $40 \mathrm{pm}(\mathrm{pmol} / \mathrm{l})$ at about $1 / 5$ to $1 / 6$ that of control subjects and did not increase after a mixed meal (C). Glucagon levels did not differ in children with or without T1DM after a mixed meal (D). Heptulla RA, et al. [16]. glucose more in T1DM than in T2DM [11]. In new-onset of young individuals with T1DM, high plasma levels of IAPP were reported [18], suggesting residual IAPP in the $\beta$-cells of new-onset type 1 diabetic individuals in contrast to the consistently lower plasma and pancreatic tissue levels in the established T1DM cases with a longer history [15]. The initial dosage of Pramlintide for subjects with T1DM is $15 \mu \mathrm{g}$ immediately before major meals, increasing by $15 \mu$ g over 3 days with a maintenance dose of 30-60 $\mu \mathrm{g}$ [17]. The initial dosage for T2DM subjects is $60 \mu \mathrm{g}$ prior to major meals, increasing to $120 \mu \mathrm{g}$ after 3-7 days with a maintenance dose of 60-120 $\mu \mathrm{g}$ [17]. Thus, it appears that subjects with T2DM are less sensitive to both insulin and IAPP actions for glycemic control compared to healthy individuals. Pramlintide is several times more expensive than insulin at present, which presents a financial burden to subjects with diabetes. Co-treatment with Pramlintide and insulin also requires a closer glucose monitoring and may not be a suitable treatment for all insulin-requiring diabetic subjects. Among my colleagues with T1DM including physicians and nurses, they prefer insulin co-injection or infusion with Pramlintide, and achieve consistently better glycemic control than insulin injection alone.

Histological and Immunocytochemical findings of islets from diabetic subjects: Based on immunocytochemical staining for islets from healthy subjects, $\beta$-cells are the major cells (60$70 \%$ ) with an abundant plump cytoplasm (Figure 4A, Table 1)[12], followed by $\alpha$-cells $(20-30 \%)$ with a small, compact cytoplasm (Figure 4C, Table 1)[12] and $\delta$-cells (about 10\%) with slightly small cytoplasm (Figure 4D)[12]. IAPP-positive cells are about $1 / 3$ of total islet cells (Figure 4B) [12] with plump staining corresponding to $60 \%$ of $\beta$-cells (Figure 4 , Table 1 ) [12]. In islets from subjects with T1DM, $\beta$-cells are reduced in proportion $(<38 \%)$ with a less abundant cytoplasm of weaker immunostaining intensity (Figure 5A) with weaker stained IAPP cells $(<20 \%)$ (Figure 5B, Table 1 ) whereas $\alpha$-cells with a compact dark staining cytoplasm are major cells $(>42 \%)$ (Figure $5 \mathrm{C}$, Table 1) [12] and $\delta$-cells are relatively increased (> 19\%) (Figure 5D, Table 1)[12]. This result underlines a markedly decreased $\beta$-cells and even more decreased IAPP-positive cells with faint immunostaining intensity and disproportionally increased $\alpha$ and $\delta$-cells, and the former cells is a cause of hyperglucagonemia inT1DM subjects (Figure 5C)[12], which further contributes to increased hepatic glucose output $[19,20]$. In those who died of diabetic coma, there were no insulin-positive cells in the background of a few residual IAPP-positive cells (Figure not shown) [12]. There are no amyloid deposits in T1DM islets as compared to ample amyloid deposits in T2DM islets (Figure not shown) $[12,13]$. T1DM develops mostly in adolescent subjects as a result of autoimmune destruction of islets, specifically targeted on $\beta$-cells in a short time frame, resulting in IAPP disappearing from $\beta$-cells without aggregating to form amyloid sheets [12]. In islets from T2DM individuals without amyloid deposits, $\beta$-cells $(<40 \%)$ are less than $\alpha$-cells $(>50 \%)$ and about $1 / 3$ of $\beta$-cells are IAPP-positive (Fig. $6 \mathrm{~A}$ and $\mathrm{C}$ ). $\beta$-cells with or without IAPPimmunostaining contained plump cytoplasm, characteristic for $\beta$-cells whereas $\alpha$-cells contain small dense cytoplasm and $\delta$-cells contain dense cytoplasm of the size between $\beta$ - and 

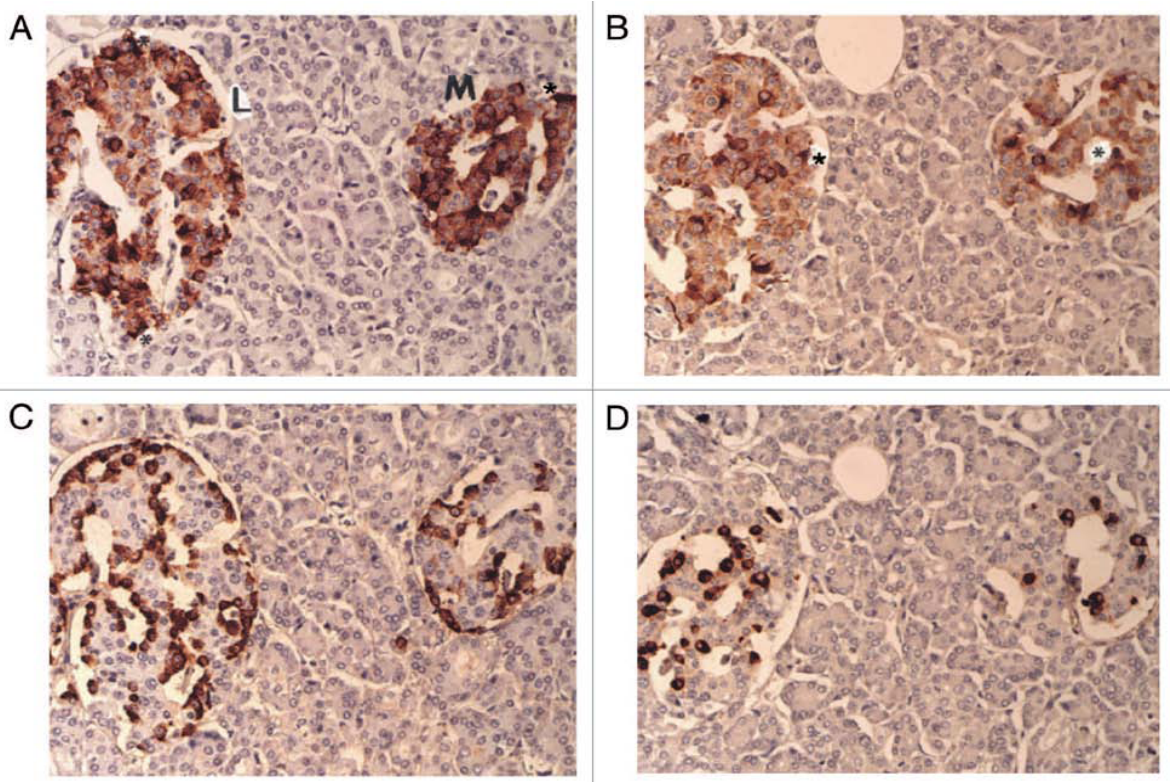

Figure 4: IAPP immunocytochemical staining for islets from a healthy control subject: $\beta$-cells are the major islet cells (about $60-70 \%)$ with an abundant cytoplasm of variable immunostaining density (A), followed by $\alpha$-cells with a densely immunostained, smaller cytoplasm (about 20-30\%)(B) and $\delta$-cells with a dense, slightly plump cytoplasm (D). IAPP-positive cells are about $1 / 3$ of total islet cells, accounting for $60 \%$ of $\beta$-cells. Both insulin and IAPP immunostaining reveals scattered, dense staining in the irregular, sickle-shaped cytoplasm with stronger immunostining for insulin than for IAPP (*). L: Large islet; M: Medium-sized islet. A: Insulin, B: IAPP, C: Glucagon, D: Somatostatin immunostained from Tomita T, [12] with permission.

$\delta$-cells (Figure 6C and D). Amyloid deposits in islets from the same subjects with T2DM vary from relatively early deposits (Figure 7B and F) to 95\% (Figure 7A and C) [13] or even to $>99 \%$ (Figure 7A and C) replaced by amyloid deposits (Figure 7) [13]. $\alpha$-cells $(60 \%)$ with dense cytoplasm are more numerous than $\beta$-cells (35\%) (Figure 7A and C)[13]. In islets 99\% replaced by amyloid deposits, there are a few residual islet cells with plump cytoplasm, representing the residual $\beta$-cells (Figure 7D and E) [13]. T2DM usually develops insidiously without typical symptoms of clinical diabetes over a longer time frame, in which islet mass initially increases to compensate for insulin demand and eventually islet mass decreases after exhaustion in the endstage [21]. Pancreatic extracts from normal humans contain a molar ratio of IAPP at $10 \%$ that of insulin and the fasting serum IAPP level in non-obese controls is $2.0 \mu \mathrm{m} / \mathrm{l}$ at $5 \%$ that of the insulin level of $48 \mu \mathrm{m} / \mathrm{l}[22,23]$, roughly corresponding to the molar ratio of plasma insulin and IAPP levels [15,22,23]. As IAPP-positive $\beta$-cell cytoplasm decreases, stromal islet amyloid deposits increase in T2DM islets [13]. In advancing stages of amyloid deposited islets, there are strongly IAPP-positive round $\beta$-cell cytoplasm without nucleus adjacent to weak IAPP-positive stromal, fine amyloid fibrils, supporting that water-soluble IAPP cytoplasm transforming to water-insoluble amyloid fibrils in the islets (Figure 7F) [13]. This round cytoplasm probably represents an aggregating form of amyloidogenic $\beta$-cell cytoplasmic proteins consisting of toxic IAPP oligomers, which may subsequently form extracellular amyloid $\beta$-sheets. This round cytoplasm is negative and stromal amyloid deposit is positive by Congo red staining [3-5]. Freshly prepared IAPP oligomers can form nonselective iron permeable membrane pores, leading to increased $\mathrm{Ca}^{2+}$ concentration, endoplasmic reticulum stress and apoptosis [26]. An in vitro study also supports that amyloid fibril formation could also commence intracellularly due to the aggregation of (pro) IAPP in lysosomes, with the nascent fibrils being released into the extracellular space upon $\beta$-cell death $[24,25]$. Plump densely IAPP-positive cells correspond to dying $\beta$-cells filled with aggregating IAPP in T2DM islets (Figure 7F) [13]. Immunocytochemical staining for IAPP in $\beta$-cells had not been reported for subjects with T2DM, instead all the previous authors had used only Congo red staining for amyloid deposits instead of IAPP Immunocytochemical staining [3-5]. Formic acid treatment used in the original extraction report of IAPP from pancreas with type 2 diabetes was also applied to the deparaffinized pancreatic tissue sections, increasing immunocytochemical staining intensity of IAPP in $\beta$-cells $[12,13,25]$.

Amyloid theory on $\beta$-cell apoptosis: IAPP has has the propensity to form membrane- permeable toxic oligomers, but it remains unclear why amyloidogenic proteins form oligomers in vivo, what their exact structure is and to what extent these oligomers play a role in the cytotoxicity and this is now often called the unfolded protein disease [23,24]. At present, the mechanism(s) underlying the formation of amyloid fibrils from normally soluble precursors remains essentially unknown [3,4,16,27-31]. According to the toxic oligomer theory, $\beta$-cells in T2DM are killed through IAPP-induced damage of the $\beta$-cell membrane [27-29]. These toxic oligomers (not monomer nor mature amyloid fibrils) eventually form the end product of $\beta$-sheets containing IAPP, $A \beta$, synuclein, transthyrenin, serum amyloid $\mathrm{P}$ component and prion protein, and share a common epitope consisting of more than 20 amyloidogenic precursor 
Table 1: IAPP immunostaining for pancreatic islets from 10 subjects with T1DM.

IAPP immunostaining for pancreatic islets from type 1 diabetics

\begin{tabular}{|c|c|c|c|c|c|c|c|c|c|c|c|c|}
\hline & \multicolumn{5}{|c|}{ Large Islets } & \multirow[b]{2}{*}{$\%$ IAPP/Ins } & \multicolumn{6}{|c|}{ Medium Islets } \\
\hline & $\begin{array}{l}\text { Total } \\
\text { Islet }\end{array}$ & $\%$ Ins & $\%$ Glu & $\%$ SRIF & \% IAPP & & Total Islet & $\%$ Ins & $\%$ Glu & $\%$ SRIF & \% IAPP & $\%$ IAPP/Ins \\
\hline Case 1. 18/M & 51.2 & 15.7 & 66.5 & 19 & 18.2 & 154 & 18.8 & 15.4 & 52.4 & 32.2 & 19.8 & 125 \\
\hline Case $2.35 / F$ & 75.1 & 0 & 66.6 & 33.5 & 8.5 & $\mathrm{NC}$ & 23 & 0 & 61.1 & 38.8 & 15.7 & $\mathrm{NC}$ \\
\hline Case 3. 39/M & 50 & 0 & 67.2 & 32.8 & 12.1 & $\mathrm{NC}$ & 18.2 & 0 & 63.8 & 36.2 & 16.7 & $\mathrm{NC}$ \\
\hline Mean $(n=3)$ & 58.2 & 5.2 & 66.7 & 28.4 & 12.9 & NC & 12.9 & 20 & 5.1 & 59.2 & 35.7 & $\mathrm{NC}$ \\
\hline SE & 8.2 & 5.2 & 0.2 & 4.7 & 2.8 & $\mathrm{NC}$ & 1.5 & 2.7 & 3.4 & 1.9 & 1.2 & $\mathrm{NC}$ \\
\hline Case $4.43 / \mathrm{F}$ & 57.6 & 37.6 & 46.6 & 16.5 & 16.7 & 44.4 & 27.8 & 41 & 43 & 16.4 & 20.8 & 52 \\
\hline Case 5. 50/F & 82 & 38.3 & 46.3 & 15.4 & 18.3 & 49.9 & 30.5 & 43 & 39.5 & 17.2 & 31 & 67.6 \\
\hline Case 6.52/F & 80.9 & 44.2 & 43.3 & 13.4 & 24.9 & 68.5 & 30.1 & 40.3 & 44.7 & 14.4 & 11.7 & 74.6 \\
\hline Ex large & 123.5 & 42.5 & 46.8 & 10 & 19.7 & 48.8 & & & & & & \\
\hline Case $7.61 / \mathrm{F}$ & 83.1 & 36.4 & 35.4 & 27.7 & 23.7 & 59.2 & 30.7 & 39.2 & 33.1 & 27.9 & 21.8 & 57 \\
\hline Ex large & 133.5 & 32.2 & 39.2 & 28.2 & 16.5 & 51.5 & & & & & & \\
\hline Case $8.65 / F$ & 39 & 30.7 & 41.3 & 27.3 & 13.3 & 46.7 & 22.4 & 28 & 49.1 & $22 . .4$ & 15 & 60.3 \\
\hline Case 9. 75/F & 87.1 & 32.8 & 51 & 16.6 & 15.5 & 52.4 & 21 & 35.8 & 39.7 & 24.4 & 26.8 & 74.7 \\
\hline Ex large & 115.4 & 32.2 & 53.9 & 14.2 & 12.2 & 43.1 & & & & & & \\
\hline Case $10.77 / F$ & 71.8 & 39.8 & 48.9 & 10.7 & 20.4 & 52.1 & 22.3 & 39.7 & 46.8 & 13.6 & 16.7 & 43 \\
\hline Ex large & 121 & 41 & 47 & 11.7 & 26.7 & 65.3 & & & & & & \\
\hline Mean $(n=7)$ & 71.6 & 36.1 & 44.7 & 19.6 & 19 & 53.3 & 26.4 & 38.1 & 42.2 & 19.5 & 20.5 & 61.2 \\
\hline SE & 6.5 & 2.4 & 2 & 3.5 & 1.6 & 3.1 & 1.6 & 1.8 & 2 & 2.1 & 2.5 & 4.4 \\
\hline $\begin{array}{l}\text { Ex large }(n=4) \\
\text { Mean }\end{array}$ & 123.2 & 37 & 46.7 & 16 & 18.7 & 52.2 & & & & & & \\
\hline SE & 3.8 & 2.7 & 3 & 4.1 & 3 & 4.7 & & & & & & \\
\hline $\begin{array}{l}\text { Controls }(\mathrm{n}=8) \\
\text { Mean }\end{array}$ & 71.3 & 58.3 & 29.1 & 11.4 & 34 & 60.8 & 23.6 & 57.6 & 27 & 14.6 & 37.8 & 65.7 \\
\hline SE & 7.2 & 3.1 & 2.6 & 1 & 2.8 & 6.4 & 1.5 & 2.7 & 2.1 & 0.7 & 1.8 & 3.8 \\
\hline
\end{tabular}

Ins, insulin; Glu, glucagon; S RIF, somtostatin; IAPP, islet amyloid polypeptide; Ex large, extra large islet; NC, not calculable.

Morphometric analysis was performed in the consecutive tissue sections from 10 cases of type 1 diabetic subjects for insulin, IAPP, glucagon and somatostatin. Islets were divided into large islets containing more than 34 islet cells and medium islets containing 14 to 33 islet cells excluding small islets with less than 14 islet cells, the latter presented a large variation of islet cell type composition from Tomita $\mathrm{T}$, [12] with permission.
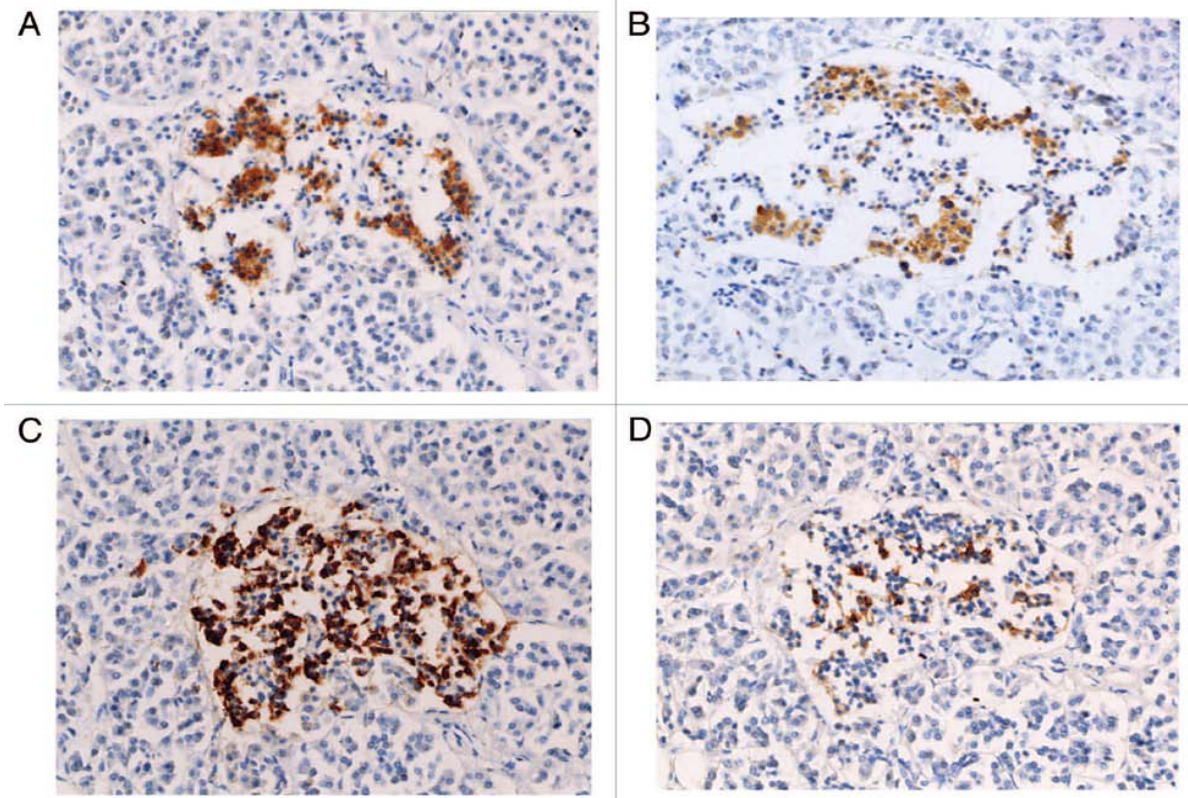

Figure 5: IAPP immunocytochemical staining for islets from a subject with T1DM : $\beta$-cells are reduced in proportion $(<36 \%)$ with less abundant cytoplasm with weaker immunostaining than control $\beta$-cells (A), replaced by major $\alpha$-cells ( $>50 \%$ ) (C) and moderately increased $\delta$-cells (15\%)(D). There are less IAPP-positive cells (25\%) (B) of weaker immunostaining intensity (B). A: Insulin, B: IAPP, C: Glucagon, D: Somatostatin immunostained from Tomita T, [13] with permission 

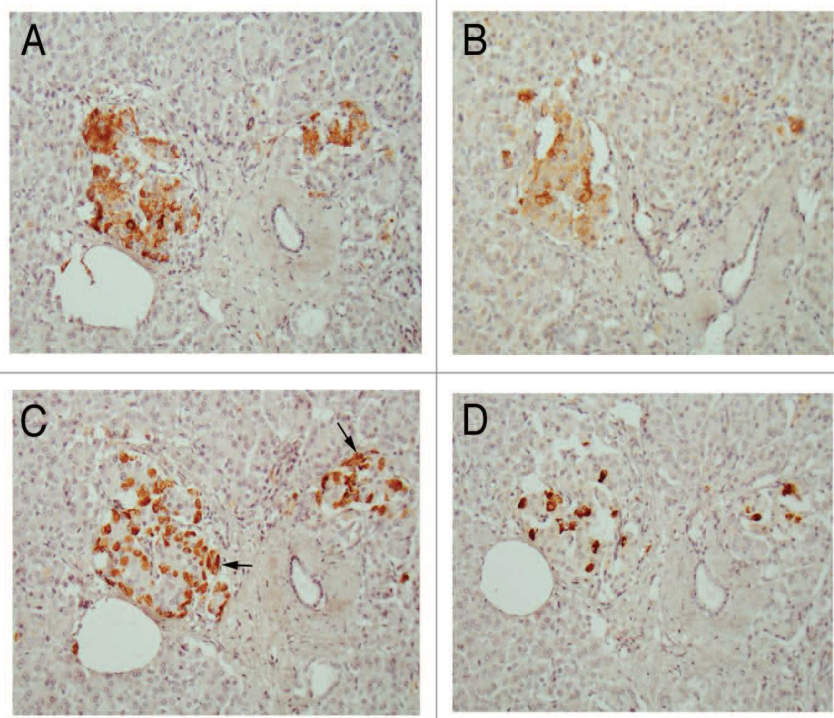

Figure 6: IAPP Immunocytochemical staining for islets from a subject with T2DM without amyloid deposits: $\beta$-cells (40\%)(A) are less than $\alpha$-cells $(50 \%)(C)$ and about $1 / 3$ of $\beta$-cells are IAPP-positive (B). $\beta$-cells with or without IAPP-immunostaining contain plump cytoplasm whereas $\alpha$-cells and $\delta$-cells contain small dense cytoplasm with $\delta$-cell cytoplasm being between sizes of $\beta$-cells and $\alpha$-cells (A, C and D).

A: Insulin, B: IAPP, C: Glucagon D: Somatostatin immunostained from Tomita T, [13] with permission
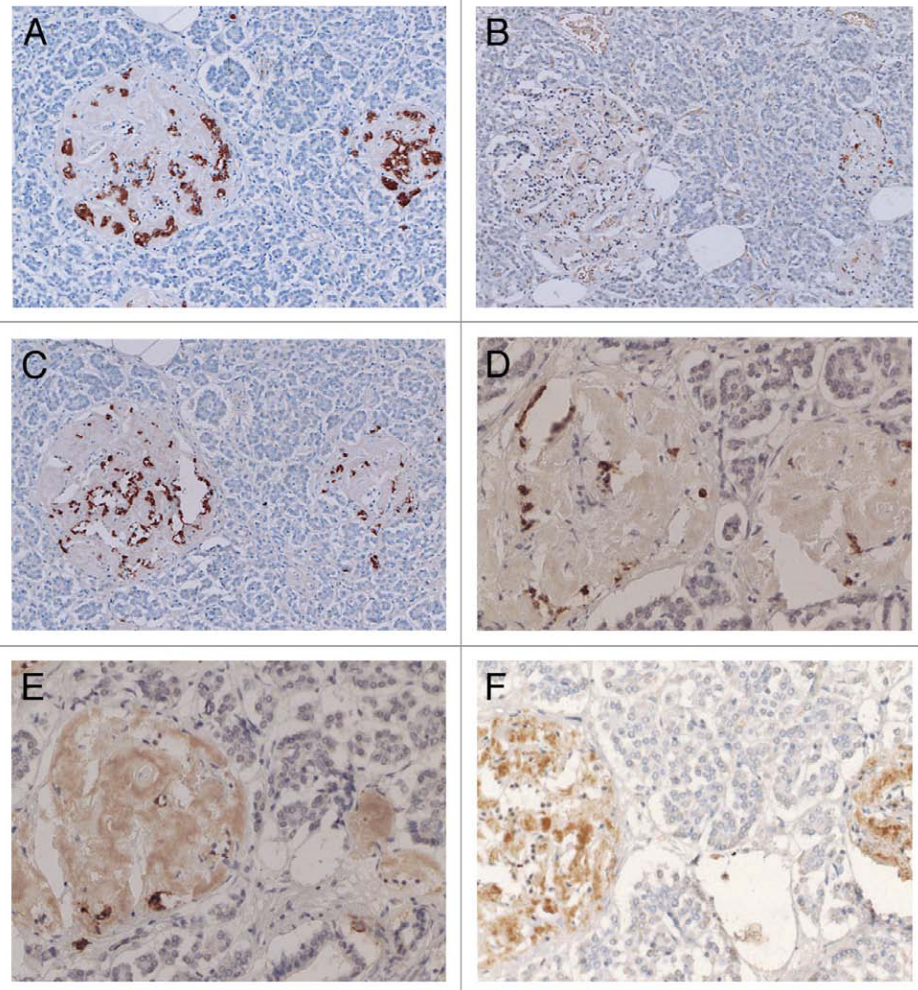

Figure 7: IAPP Immunocytochemical staining for islets from a subject with T2DM with amyloid deposit. Amyloid deposits replaced 95\% (A-C) to > 99\% of islet areas (D-F). Both large islets (left islet) and medium-sized islet (right islet) are about 95\% replaced by amyloid deposits, within which $\beta$-cells have a mostly plump cytoplasm (A) whereas $\alpha$-cells have a small compact cytoplasm (C). Islets occupied at $>99 \%$ have residual $\beta$-cells (D). Islets replaced at $50 \%$ by amyloid deposits are almost completely negative for IAPP immunostaining (B) whereas islets of amyloid deposits replaced $>99 \%$ of the islets contain disproportionally more strongly IAPP- immunopositive residual $\beta$-cells (E). Some residual round $\beta$-cell cytoplasm in less markedly replaced by amyloid deposited islets is strongly and stromal amyloid deposits are weakly positive for IAPP (F).These strongly IAPP-immunopositive, round cytoplasm without a nucleus may represent unfolded IAPP oligomers, which leads to $\beta$-cell death and subsequent extracellular and intra-islet amyloid sheet formation (F). A and D: Insulin, B, E and F: IAPP, C: Glucagon immunostained from Tomita, T [13] with permission. 
proteins $[2,3,5,26]$. Amyloid $\mathrm{p}$ is a universal immunologic and immunologic marker for all types of amyloidosis [1-5,27]. Freshly prepared intermediate IAPP polymers (25 ---6000 IAPP molecules) have a toxic effect on $\beta$-cells but do not exhibit a toxic effect on $\sigma, \delta$ and PP islet cells since non- $\beta$-cells do not contain enough endogenous IAPP [26]. Water-soluble IAPP with low molecular weight in $\beta$-cell granules is readily and densely immunostained for IAPP whereas water-insoluble amyloid fibrils containing IAPP polymers are only weakly immunostained for IAPP (Figure 7E) [13]. This weak IAPP immunocytochemical staining for intra-islet stromal amyloid deposit was only achieved after deparaffinized pancreatic tissue sections are treated with formic acid as the same way that IAPP was isolated originally from pancreatic tissue from subjects with T2DM $[1,13]$. This lack of strong IAPP immunostaining for amyloid deposit is not clear but one possible reason is that the unexposed epitope of IAPP polymers within water-insoluble amyloid fibrils forms a $\beta$-sheet conformation that anti-IAPP antibodies cannot penetrate to bind IAPP molecule $[14,26]$. Antibodies generated to this epitope using toxic $A \beta_{1-40}$ also bind toxic oligomers generated from the other amyloidogenic protein in cell culture and block the cytotoxic effects of each of these diverse oligomers [32]. More recently, glucagon-like peptide-1 receptor agonist restored impaired prohIAPP processing and reduced hIAPP aggregation in cultured human islets by enhancing survival and function of human islets [33]. A hIAPP inhibitor peptide, D-ANFLVH, is a potent inhibitor of islet amyloid deposition and reduced islet cell apoptosis in a human IAPP transgenic mouse model [33]. These and other works are still of preclinical stage and will need some more time until solid clinical application becomes feasible. Butler and his associates [21] tested the hypothesis that $\beta$-cells are preferably vulnerable to hIAPP-induced apoptosis with isolated human islets in tissue culture: Apoptotic cells by TUNEL were increased fivefold after incubation with $40 \mu \mathrm{m} / \mathrm{l}$ hIAPP compared with control islets. Further, in T2DM islets, the apoptotic cells in islets were binucleated, suggesting that cells underwent apoptosis shortly after mitosis [32]. The question whether amyloid deposit is the cause or the result of T2DM still remains but islet amyloid is clearly linked to the pathophysiology of T2DM [3-6,16,25-30]. In early stages of T2DM, a combined depletion of insulin and IAPP in $\beta$-granules causes early stages of hyperglycemia, and IAPP in $\beta$-granules is somehow intracellularly transformed into cytotoxic IAPP oligomer, which kills $\beta$-cells in situ, and subsequent formation of extracellular amyloid sheets in islets is the end stage of T2DM islets (Figure 7E)[13]. Displacement of islets by amyloid sheets contributes to chronic sustaining hyperglycemia physically encircling the remaining $\beta$-islet cells and obstructing insulin secretion and transport into the blood. In addition to IAPP involvement in $\beta$-cell apoptosis, other elements may well be involved in the pathogenesis of $\beta$-cell apoptosis since not all islets from T2DM subjects contain amyloid deposits $[3,5,13]$. The early event of $\beta$-cell dysfunction includes ER stress, mitochondrial dysfunction, oxidative stress and glucotoxicity [35]. There is a constant demand from the body for insulin biosynthesis and secretion and baseline endoplasmic reticulum (ER) stress levels appear to be high in $\beta$-cells [32]. Evidence suggests that cellular stress caused by the accumulation of unfolded and misfolded protein in the ER is related to $\beta$-cell dysfunction and apoptosis in T2DM [36]. ER can sense and transduce apoptotic signals since various genetic and environmental stresses interfere with protein folding in the ER and induce ER stress in $\beta$-cells [36,37].

\section{References}

1. Westermark P, Westermark C, Wilander E, Sletten K. A novel peptide in the calcitonin gene related peptide family as an amyloid fibril protein in the endocrine pancreas. Biochem Biophys Res Commun. 1986;140(3):827-831.

2. Cooper GJ, Willis AC, Clark A, Tumer RC, Sim RB, Reid KB. Purification and characterization of a peptide from amyloid-rich pancreas of type 2 diabetic pancreas. Proc Natl Acad Sci USA. 1987;84(3):8628-8632.

3. Hoppener JW, Ahren B, Lips CJ. Islet amyloid and type 2 diabetes mellitus. N Eng J Med. 2000;343(6):411419.

4. Hull RI, Westermark GT, Westermark P, Kahn SE. Islet amyloid. a critical entity in the pathogenesis of type 2diabetes. J Clin Endocrinol Metab. 2004;89(8):3629-3643.

5. Westermark P, Andersson A, Westermark GT. Islet amyloid polypeptide, islet amyloid, and diabetes mellitus. Physiol Rev. 2011;91(3):795-826.

6. Kahn SE, Andrikopoulos S, Verchere CBN. Islet amyloid: a longrecognized but underappreciated pathological feature of type 2 diabetes. Diabetes. 1999;48(2):241-253.

7. Buse JB, Weyer C, Maggs DC. Amylin replacement with Pramlintide in type 1 and type 2 diabetes: a physiological approach to overcome a barrier with insulin therapy. Clin Diabetes. 2002;20(3):137-144.

8. Fineman M, Weyer C, Maggs DG, Strobel S, Kolterman OG. The human amylin analog, pramlintide, reduces postprandial hyperglucagonemia in patients with type 2 diabetes mellitus. Horm Metab Res. 2002;34(9):504-508.

9. Kruger DF, Gatcomb PM, Owen SK. Clinical implication of amylin and amylin deficiency. Diabetes Educ. 1999;25(3):389-397.

10. Weyer C, Maggs DG, Young AA, Kohlman OG. Amylin replacement with pramlintide as an adjunct to insulin therapy in type 1 and type 2 diabetes mellitus: a physiological approach toward improved metabolic control. Curr Pharm Des. 2001;7(18):1353-1373.

11. Maggs DG, Fineman, Kornstein J, Burell T, Schwartz S, Wang Y, et al. Pramlintide reduces postprandial glucose excursions when added to insulin lispro in subjects with type 2 diabetes: a dose-timing study. Diabetes Metab Res Rev. 2004;20(1):55-60.

12. Tomita, T: Islet amyloid polypeptide in pancreatic islets from type 1 diabetic subjects. Islets 2011, 3:166-174.

13. Tomita T. Islet amyloid polypeptide in pancreatic islets from type 2 diabetes subjects. Islets. 2012;4(3):223-232.

14. Pullman J, Darsaw T, Frias JP. Pramlintide in the management in he management of insulin-using patients with type 2 and type 1 diabetes. Vasc Health Risk Manag. 2006;2(3):203-212.

15. Kruger DF, Gloster, MA. Pramlintide for the treatment of insulinrequiring diabetes mellitus: A rationale and review of clinical data. Drugs. 2004;64(13):1419-32.

16. Heptulla RA, Rodriguez LM, Bomgasars L, Haymond MW. The role of amylin and glucagon in the dampening of glycemic excursions in children with type 1 diabetes. Diabetes. 2005;54(4):1100-7. 
17. Jones MC. Therapies for diabetes: Pramlintide and Exenatide. Am Fam Physician. 2007;75(12):1831-5.

18. Paulsson JF, Ludvigsson J, Carlsson A, Casas R, Fordander G, et al: High plasma levels of islet amyloid polypeptide in young with new-onset type 1 diabetes mellitus. PLoS One. 2014;9(3):e93053.

19. Arnoff SL, Berkowitz K, Streiner B, Want L. Glucose metabolism and regulation: Beyond insulin and glucagon. Diabetes Spectrum. 2004;17(3):183-190

20. Cooperber BA, Cryer PE. Insulin reciprocally regulates glucagon secretion in humans. Diabetes. 2010;59(11):293640.

21. Butler AE, Janson J, Bonner-Weir S, Ritzel RT, Rizza RA, Butler PC. $\beta$-cell defect and increased $\beta$-cell apoptosis in humans with type 2 diabetes. Diabetes. 2003;52(1):102-10.

22. Clark A, Nilsson MR. Islet amyloid: a complication of islet dysfunction or an aetiological factor in type 2 diabetes? Diabetologia. 2004;47(2):157-69.

23. Clark A, Wells CA, Buley ID, Cruickshank JK, Vanhegan RI, et al. Islet amyloid, increased A-cells, reduced-B-cells and exocrine fibrosis quantitative changes in the pancreas in type 2 diabetes. Diabetes Res. 1988;9(4):151-9.

24. Haataja L, Gurlo T, Huang CJ, Huang CJ, Butler PC. Islet amyloid in type 2 diabetes and the toxic oligomer hypothesis. Endocr Rev. 2008;29(3):303-16.

25. Tomita T. Apoptosis of pancreatic $\beta$-cells in type 1 and type 2 diabetes In: Islets of Langerhans, S. Islam, Eds. Springer; 2014. p. 845-872.

26. Tomita T. Amyloidosis of pancreatic islets in primary amyloidosis (AL type). Pathol Int. 2005;55(4):223-7.

27. Akter R, Cao P, Noor H, Ridgway Z, Tu LH, Wang H, Wong AG, et al. Islet amyloid polypeptide: Structure , function and pathophysiology. J Diabetes Res. 2016;2016:2798269.
28. Mirzabekov TA, Lin MC, Kegan B. Pore formation by the cytotoxic islet amyloid peptide amylin. J Biol Chem. 1996;271(4):1988-92.

29. Anguiano M, Nowak RJ, Lansbury PTJr. Protofibrillar islet amyloid polypeptide permeabilizes synthetic vesicles by a pore-like mechanisms that may be relevant to type II diabetes. Biochemistry. 2002;41(38):11338-43.

30.Jansen A, Van Hagen M, Drexhage HA. Defective mutation and function of antigen-presenting cells in type 1 diabetes. Lancet. 1995;345(8948):491-2.

31. Kayed R, Head E, Thompson JI, McIntyre TM, Milton SC, Cotman CW, et al. Common structure of soluble amyloid oligomers implies common mechanism of pathogenesis. Science. 2003;300(5618):486-9.

32. Ritzel RA, Butler PC. Replication increases $\beta$-cell vulnerability to human islet amyloid polypeptide-induced apoptosis. Diabetes. 2003;52(7):1701-8.

33. Park YJ, Ao Z, Kieffer J, Chen H, Safkhan N, Thompson DM, et al. The glucagon-like peptide-1 agonist exenatide restores impaired pro-islet amyloid polypeptide processing in culture human islts: implication in type 2 diabetes and islet transplantation. Diabetologia. 2013;56(3):508-19.

34. Wijesekara N, Ahrens R, Wu L, Ha K, Liu Y, Wheler MB, et al. Islet amyloid inhibitors improve glucose homeostasis in a transgenic model model of type 2 diabetes. Diabetes Obes Metab. 2015;17(10):1003-6.

35. Pentki M, Nolan CJ. Islet $\beta$-cell failure in type 2 diabetes. J Clin Invest. 2006;116(7):1802-12.

36. Kataoka H, Noguchi H. ER stress and $\beta$-cell pathogenesis of type 1 and type 2 diabetes and islet transplantation. Cell Med. 2013;5(2-3):53-7.

37. Oyadomari S, Mori M. Endoplasmic reticulum stress-mediated apoptosis in pancreatic $\beta$-cells. Apoptosis. 2002;7(4):33545. 